\title{
Left Lobe of the Liver
}

National Cancer Institute

\section{Source}

National Cancer Institute. Left Lobe of the Liver. NCI Thesaurus. Code C32965.

The smaller lobe of the liver extending into the left side of the body. 